\title{
Pengaruh Pemberian Posisi Lateral Terhadap Saturasi Oksigen dan Frekuensi Pernapasan pada Anak dengan Gangguan Pemenuhan Kebutuhan Oksigenasi di Ruang Rawat Infeksi Anak
}

\author{
The Effect Of Lateral Position In Improving Oxygen Saturation And Respiratory Rate In \\ Children With Oxygenation Problem In Pediatric Infection Ward
}

\author{
Paskaliana Hilpriska Danal ${ }^{1,2}$, Nani Nurhaeni ${ }^{2}$, Dessie Wanda ${ }^{2}$ \\ ${ }^{1}$ Program Studi Keperawatan, Fakultas IImu Kesehatan, UNIKA Santu Paulus Ruteng, \\ ${ }^{2}$ Program Studi Magister IImu Keperawatan, Fakultas IImu Keperawatan, Universitas Indonesia, \\ Depok, Indonesia
}

Korespodensi penulis:

Paskaliana Hilpriska Danal

E-mail: paskaliana.danal@gmail.com

\begin{abstract}
Abstrak
Latar Belakang: Masalah pemenuhan kebutuhan oksigenasi pada anak sering disebabkan oleh ketidakpatenan jalan napas sehingga modifikasi posisi tubuh salah satunya posisi lateral untuk meningkatkan kelancaran oksigenasi pada anak merupakan intervensi yang efektif. Study ini bertujuan untuk mengidentifikasi pengaruh pemberian posisi lateral terhadap perubahan saturasi oksigen dan frekuensi pernapasan pada anak dengan gangguan pemenuhan kebutuhan oksigenasi di ruang rawat infeksi anak. Metode: Desain kuasi eksperimen. Responden dalam study ini berjumlah 36 orang yang dibagi ke dalam kelompok pemberian posisi lateral dan kelompok yang diberikan posisi sesuai standar perawatan rumah sakit sebagai kontrol, masing-masing 18 responden. Pengumpulan data dilakukan dengan mengukur saturasi oksigen dan frekuensi pernapasan sebelum dan sesudah diberikan intervensi. Analisis data menggunakan uji paired $t$-test dan Wilcoxon untuk menilai adanya perbedaan saturasi oksigen dan frekuensi pernapasan anak sebelum dan sesudah intervensi. Uji independent $t$-test dan Mann Whitney digunakan untuk menganalisis perbedaan saturasi oksigen dan frekuensi pernapasan antar kelompok. Hasil: analisis statistik menunjukkan terdapat perbedaan signifikan antara saturasi oksigen ( $p$ value $<0,05)$ dan frekuensi pernapasan ( $p$ value $<0,05$ ) sebelum dan sesudah diberikan posisi lateral. Kesimpulan: posisi lateral dapat dijadikan salah satu intervensi keperawatan mandiri yang dapat diterapkan dalam memberikan asuhan pada anak dengan masalah pemenuhan kebutuhan oksigenasi di ruang rawat.
\end{abstract}

Kata Kunci: Anak; Frekuensi Pernapasan; Posisi Lateral; Saturasi Oksigen

\begin{abstract}
Background: Oxygenation problems in children is mostly caused by inefective airway patency, thus body position modification such as lateral positioning is an effective measure to increase the oxygenation in children. This study was aimed to identify the effect of lateral position in improving oxygen saturation and respiratory rate in children with oxygenation problem in pediatric infection ward. Methods: quasi expermental design. The respondents were 36 children divided into two groups: intervention group who received lateral position and control group who received standard hospital positioning and care with 18 respondents each group. The data collection used by measuring oxygen saturation level and respiratory rate before and after given the intervention. The data analysis used paired t-test and Wilcoxon test to compare the oxygen saturation level and respiratory rate before and after given the intervention. Independent $t$ - test and Mann Whitney test were used to compare the oxygen saturation level and respiratory rate between groups. Results: The statistic analysis showed that there were significant difference between the oxygen saturation level ( $p$ value $<0,05)$ and respiratory rate $(p$ value $<0,05)$ before and after given the intervention. Conclusion: lateral position can be used as an independent nursing intervention for hospitalized children with oxygenation problems.
\end{abstract}

Keywords: Children; Lateral Position; Oxygen Saturation; Respiratory Rate 


\section{Pendahuluan}

Masalah pernapasan khususnya pneumonia merupakan salah satu penyebab terbanyak anak memerlukan perawatan di rumah sakit di negara berkembang termasuk Indonesia. ${ }^{1,2}$ Perawatan anak di rumah sakit akibat pneumonia di Indonesia mencapai 960 kasus dalam satu tahun dan menjadi masalah kesehatan dan ekonomi yang vital bagi Indonesia ${ }^{2}$. Berdasarkan hasil pengkajian di ruang rawat infeksi anak di salah satu rumah sakit rujukan di DKI Jakarta, diketahui bahwa rerata anak dengan pneumonia yang dirawat per hari adalah sekitar 4 anak atau $20 \%$ dari total keseluruhan anak yang dirawat.

Pneumonia merupakan salah satu penyebab terjadinya distres pernapasan pada anak yang dirawat inap dan memerlukan manajemen yang akurat agar anak tidak berada dalam kondisi distres pernapasan. ${ }^{3}$ Sekitar 35\% terjadinya sindrom distres pernapasan pada anak adalah akibat pneumonia. ${ }^{4}$ Dispnea, batuk, demam, tersedak dan peningkatan frekuensi pernapasan merupakan beberapa tanda pneumonia. ${ }^{5}$ Dispnea atau sesak napas merupakan salah satu gejala umum pneumonia di mana anak mengalami kesulitan bernapas. ${ }^{6}$ Kecemasan atau ketakutan dapat memperberat sesak napas dan memengaruhi ekspansi paru, meningkatkan risiko komplikasi pulmonar dan memperlama waktu rawat. ${ }^{7}$ Pada anak, kecemasan sering terjadi akibat stres hospitalisasi yang dapat memperberat sesak napas yang dialami.

Manajemen penanganan masalah oksigenasi pada anak dapat didahului dengan pengkajian riwayat keluhan dan pemantauan kondisi yang komprehensif. Pada anak dengan pneumonia, pemantauan yang perlu dilakukan adalah nilai saturasi oksigen dan status kardiorespirasi. ${ }^{8}$ Tatalaksana pada anak dengan gangguan pemenuhan masalah oksigenasi meliputi manajemen penyebab penyakit, terapi suportive dan simptomatik seperti oksigen, antipiretik dan cairan. ${ }^{5}$ Selain itu, pemberian posisi juga diperlukan untuk memastikan keefektifan pertukaran gas. Salah satu posisi tubuh yang diketahui meningkatkan ekspansi paru adalah posisi lateral (baik kanan maupun kiri) yakni dengan peningkatan elastisitas dinding dada sebesar 3 $\mathrm{cmH} 2 \mathrm{O} / \mathrm{L}$ dan elastisitas paru sebesar 2 $\mathrm{cmH} 2 \mathrm{O} / \mathrm{L}$ serta meningkatkan resistensi jalan napas sebesar $2 \mathrm{cmH} 2 \mathrm{O} / \mathrm{L}^{9}$ Penelitian sebelumnya mengungkapkan bahwa posisi lateral merupakan posisi yang baik untuk mempertahankan kepatenan jalan napas anak. ${ }^{10}$ Sehingga, posisi lateral diketahui akan memfasilitasi peningkatan ekspansi paru yang membantu pemenuhan 
kebutuhan oksigenasi pada anak yang mengalami pneumonia.

Masalah utama yang terjadi pada anak dengan gangguan pemenuhan oksigenasi di rumah sakit adalah sesak napas akibat penumpukan sekret jalan napas dan ketidakpatenan jalan napas.Oleh karenanya, pemberian posisi lateral ini diharapkan dapat meningkatkan saturasi oksigen serta menurunkan frekuensi pernapasan pada anak dengan gangguan pemenuhan kebutuhan oksigen di ruang rawat infeksi anak RSCM. Study ini diharapkan dapat menjadi panduan bagi perawat dalam memberikan posisi yang tepat bagi anak dengan gangguan pemenuhan kebutuhan oksigenasi sehingga frekuensi pernapasan menjadi normal dan saturasi oksigen meningkat. Hasil study ini diharapkan menjadi salah satu pertimbangan rumah sakit untuk menyusun prosedur tindakan dan meningkatkan pengetahuan orang tua atau pengasuh dalam memberikan posisi pada anak untuk memfasilitasi peningkatan oksigen ke seluruh tubuh anak dan meningkatkan kenyamanan anak untuk bernapas.

\section{Metode}

Identifikasi masalah dalam study ini menggunakan analisis PICO (Population, Intervention, Comparisson dan Outcome) dengan rincian sebagai berikut: populasi adalah anak dengan masalah pemenuhan oksigenasi; intyervensi yang dilakukan adalah pemberian posisi lateral, sebagai pembanding terhadap pemberian posisi standar rumah sakit dan hasil yang diharapkan adalah frekuensi pernapasan dan saturasi oksigen dalam batas normal. Perekrutan responden dilakukan dengan metode consecutive dengan kriteria inklusi anak dengan masalah pemenuhan kebutuhan oksigenasi yang ditandai dengan sesak napas (RR lebih dari normal) dan tidak memiliki kontraindikasi diberikan posisi (mis. fraktur atau post operasi yang memerlukan tirah baring) sedangkan kriteria eksklusi adalah anak yang mengalami penurunan kondisi (PEWS meningkat $\geq 3$ ). Pembagian sampel ke dalam kelompok intervensi maupun kontrol dilakukan dengan teknik insidentil yakni yang ditemui terlebih dahulu dimasukan ke dalam kelompok intervensi sampai memenuhi jumlah sample yang diperlukan. Terdapat dua kelompok yang terlibat yakni kelompok pemberian posisi lateral dan kelompok kontrol. Masing-masing kelompok terdiri atas 18 anak dengan gangguan pemenuhan kebutuhan oksigenasi. Kemudian dilakukan pengukuran saturasi oksigen dan frekuensi pernapasan sebelum pemberian posisi lateral dan 60 menit pasca intervensi. 
Prosedur pemberian posisi lateral dilakukan dengan menentukan posisi lateral yang nyaman bagi anak apakah lateral kiri atau lateral kanan. Pemberian posisi lateral pada kelompok intervensi dan posisi standar pada kelompok kontrol ini dilakukan oleh peneliti dan perawat ruangan yang merawat anak. Pemantauan pertahanan posisi selama 60 menit satu kali perlakuan, dilakukan oleh ibu atau penjaga anak setelah diberikan edukasi dan penjelasan oleh peneliti dan perawat. Posisi lateral kiri atau kanan diberikan secara kontinyu selama 60 menit tanpa berpindah posisi. Prosedur pemberian posisi dapat dilihat pada tabel 1. Data saturasi oksigen dan frekuensi pernapasan sebelum intervensi dilakukan uji homogenitas untuk memastikan kesetaraan data. Uji normalitas dilakukan sebelum analisis sebagai syarat pemilihan uji statistik yang tepat. Kemudian dilakukan analisis data menggunakan uji Wilcoxon, uji Paired t-test dan Mann-Whitney. Study ini telah mendapat ethical clearance dari komite etik RSPI Prof Dr Sulianti Saroso dengan nomor izin etik 26/XXXVIII.10/IX/2021.

\section{Hasil}

Karakteristik responden yang diidentifikasi meliputi usia, jenis kelamin, kategori diagnosis penyakit dan status gizi anak. Karakteristik responden tersebut merupakan data kategorik.
Pada kelompok pemberian posisi lateral, karakteristik responden sebagian besar berkategori usia bayi (112 bulan), berjenis kelamin laki-laki, kategori penyakit sistem respirasi dan status gizi kurang. Sedangkan pada kelompok kontrol, karakteristik responden sebagian besar berkategori usia bayi (1-12 bulan), berjenis kelamin laki-laki, kategori penyakit sistem respirasi dan status gizi kurang dan baik (Tabel 1).

Rerata saturasi oksigen sebelum pemberian posisi lateral adalah 97,11 dan sesudah adalah 97,78. Hasil analisis lanjut dengan uji Wilcoxon diperoleh $p$ value $=0,007<\alpha(0,05)$ maka dapat dijelaskan bahwa ada perbedaan bermakna saturasi sebelum (pretest) dan sesudah (posttest) pemberian posisi lateral. Hal ini menunjukkan bahwa ada perbedaan bermakna pemberian posisi lateral terhadap kenaikan saturasi oksigen pada anak dengan gangguan pemenuhan kebutuhan oksigen di ruang rawat infeksi anak. Pada kelompok kontrol, rerata saturasi oksigen sebelum pemberian posisi lateral adalah 98,06 dan sesudah adalah 97,72. Hasil analisis lanjut dengan uji paired $t$ test diperoleh $p$ value $=0,138>\alpha(0,05)$ maka dapat dijelaskan bahwa tidak ada perbedaan bermakna saturasi sebelum 
(pretest) dan sesudah (posttest) pada kelompok kontrol (Tabel 2).

Rerata frekuensi pernapasan sebelum pemberian posisi lateral adalah 43,22 dan sesudah adalah 35,33 . Hasil analisis lanjut dengan uji paired $t$ test diperoleh $p$ value $=0,000<\alpha(0,05)$ maka dapat dijelaskan bahwa ada perbedaan bermakna frekuensi pernapasan sebelum (pretest) dan sesudah (posttest) pemberian posisi lateral. Pada kelompok kontrol rerata frekuensi pernapasan sebelum pemberian posisi lateral adalah 42,06 dan sesudah adalah 42,50. Hasil analisis lanjut dengan uji paired $t$ test diperoleh $p$ value $=0,515>\alpha(0,05)$ maka dapat dijelaskan bahwa tidak ada perbedaan bermakna frekuensi pernapasan sebelum (pretest) dan sesudah (posttest) pada kelompok kontrol (Tabe 2).

Tabel 1. Karakteristik pasien anak dengan gangguan pemenuhan kebutuhan oksigen di ruang rawat infeksi anak $(n=36)$

\begin{tabular}{|c|c|c|c|c|c|c|}
\hline \multirow[t]{3}{*}{ Karakteistik } & \multicolumn{4}{|c|}{ Kelompok } & \multicolumn{2}{|c|}{ Total } \\
\hline & \multicolumn{2}{|c|}{ Intervensi } & \multicolumn{2}{|c|}{ Kontrol } & \multirow[b]{2}{*}{$\mathbf{n}$} & \multirow[b]{2}{*}{$\%$} \\
\hline & $\mathbf{n}$ & $\%$ & $\mathbf{n}$ & $\%$ & & \\
\hline \multicolumn{7}{|l|}{ Usia } \\
\hline - Bayi (1-12 Bulan) & 7 & 38,9 & 8 & 44.4 & 15 & 41,7 \\
\hline - Toddler (1-3 Tahun) & 5 & 27,8 & 2 & 11.1 & 7 & 19,4 \\
\hline - Pra Sekolah (3-5 Tahun) & 4 & 22,2 & 1 & 5.6 & 5 & 13,9 \\
\hline - Sekolah (5-12 Tahun) & 1 & 5,6 & 2 & 11.1 & 3 & 8,3 \\
\hline - Remaja (12-18 Tahun) & 1 & 5,6 & 5 & 27.8 & 6 & 16,7 \\
\hline \multicolumn{7}{|l|}{ Jenis Kelamin } \\
\hline - Laki-Laki & 12 & 66,7 & 13 & 72.2 & 25 & 69,4 \\
\hline - Perempuan & 6 & 33,3 & 5 & 27.8 & 11 & 30,6 \\
\hline \multicolumn{7}{|l|}{ Diagnosa Penyakit } \\
\hline - Respirasi & 12 & 66,7 & 11 & 61.1 & 23 & 63,9 \\
\hline - Persyarafan & 2 & 11,1 & 2 & 11.1 & 4 & 11,1 \\
\hline - Perkemihan & 0 & 0 & 2 & 11.1 & 2 & 5,6 \\
\hline - Kardiovaskuler & 1 & 5,6 & 0 & 0 & 1 & 2,8 \\
\hline - Penncernaan & 1 & 5,6 & 2 & 11.1 & 3 & 8,3 \\
\hline - Imun & 1 & 5,6 & 0 & 0 & 1 & 2,8 \\
\hline - Hematologi & 1 & 5,6 & 1 & 5.6 & 2 & 5,6 \\
\hline \multicolumn{7}{|l|}{ Status Gizi } \\
\hline - Kurang & 11 & 61,1 & 9 & 50 & 20 & 55,6 \\
\hline - Baik & 6 & 33,3 & 9 & 50 & 15 & 41,7 \\
\hline - Lebih & 1 & 5,6 & 0 & 0 & 1 & 2,8 \\
\hline
\end{tabular}


Tabel 2. Perbedaan saturasi oksigen dan frekuensi pernapasan pada anak dengan gangguan pemenuhan kebutuhan oksigen di ruang rawat infeksi anak pada kelompok pemberian posisi lateral maupun kontrol $(n=36)$

\begin{tabular}{|c|c|c|c|c|c|}
\hline Saturasi oksigen & $\mathbf{n}$ & Mean & Median & $\begin{array}{l}\text { Standar } \\
\text { deviasi }\end{array}$ & $p$ value \\
\hline \multicolumn{6}{|l|}{ Pemberian posisi lateral } \\
\hline Sebelum & 18 & 97,11 & 98,00 & 3,94 & \multirow[t]{2}{*}{$0.007^{a}$} \\
\hline Sesudah & 18 & 97,78 & 98,50 & 2,82 & \\
\hline \multicolumn{6}{|l|}{ Kontrol } \\
\hline Sebelum & 18 & 98,06 & 98,00 & 1,16 & \multirow[t]{2}{*}{$0,138^{a}$} \\
\hline Sesudah & 18 & 97,72 & 98,00 & 1,13 & \\
\hline Frekuensi pernapasan & $\mathbf{n}$ & & Mean & $\begin{array}{l}\text { Standar } \\
\text { deviasi }\end{array}$ & $p$ value \\
\hline \multicolumn{6}{|l|}{ Pemberian posisi lateral } \\
\hline Sebelum & 18 & 43,32 & 43,22 & 10,58 & \multirow{2}{*}{0,000} \\
\hline Sesudah & 18 & 35,33 & 35,33 & 8,04 & \\
\hline \multicolumn{6}{|l|}{ Kontrol } \\
\hline Sebelum & 18 & 42,06 & 42,06 & 16,57 & \multirow{2}{*}{0,515} \\
\hline Sesudah & 18 & 42,50 & 42,50 & 15,91 & \\
\hline
\end{tabular}

Keterangan: a: $p$ value uji Wilcoxon (data terdistribusi tidak normal); b: $p$ value uji paired $t$ test (data terdistribusi normal)

\section{Pembahasan}

Posisi tubuh pada anak diketahui berpengaruh terhadap pernapasan dan fungsi paru-paru. Pada umumnya, posisi tubuh yang tepat dapat membantu meningkatkan transportasi oksigen dengan memanfaatkan efek gravitasi pada fungsi paru dan jantung. ${ }^{11}$ Pengaruh gravitasi ini terbukti pada perubahan kapasitas fungsional residual paru pada berbagai posisi. ${ }^{12}$ Penelitian terdahulu telah mengidentifikasi bahwa posisi tubuh anak memengaruhi luasnya volume paru yang dapat membantu peningkatan kepatenan jalan napas anak. ${ }^{9,10}$ Oleh karena itu, perawatan anak dengan gangguan pemenuhan kebutuhan oksigen memerlukan pemberian posisi yang tepat sehingga dapat memaksimalkan terapi.
Pemberian posisi lateral ini menunjukkan bahwa terdapat peningkatan saturasi oksigen yang bermakna setelah diberikan intervensi selama 1 jam. Sedangkan pada kelompok kontrol tidak terjadi perubahan bermakna pada saturasi oksigen. Saturasi oksigen meningkat signifikan dalam 40 menit jika diberikan posisi lateral kiri dengan sudut $45^{\circ}$.Perbedaan saturasi ini disebabkan oleh adanya penyebaran cairan interstisial paru. Pada klien dengan penyakit paru bilateral, cairan interstisial cenderung berkumpul di bagian bawah paru sehingga posisi supinasi menyebabkan cairan menyebar ke bagian atas paru dan mengganggu perfusi. ${ }^{13}$ Hasil penelitian ini juga sejalan dengan penelitian sebelumnya yang mengemukakan bahwa posisi lateral 
dapat meningkatkan saturasi oksigen dan menurunkan episode gangguan pernapasan pada anak dengan obstructive sleep apnea (OSA) ${ }^{14}$

Hasil penerapan pemberian posisi lateral pada anak dengan gangguan pemenuhan oksigen ini menunjukkan terdapat perbedaan signifikan pada frekuensi pernapasan sebelum dan sesudah intervensi. Sedangkan pada kelompok kontrol tidak terdapat perbedaan bermakna pada frekuensi pernapasan. Hal ini sejalan dengan penelitian sebelumnya yang mengatakan bahwa frekuensi pernapasan pada bayi dengan distres pernapasan cenderung menjadi menurun setelah diberikan posisi. ${ }^{15}$ Posisi lateral diketahui memengaruhi mekanisme pernapasan dengan meningkatkan keelastisan dinding paru dan dada sebesar $2-3 \mathrm{cmH}_{2} \mathrm{O} .^{9}$ sehingga oksigen lebih dapat masuk dengan baik dan membantu pertukaran gas

Setelah dianalisis perbandingan saturasi oksigen dan frekuensi pernapasan antara kelompok pemberian posisi lateral dan kelompok kontrol, diketahui tidak terdapat perbedaan yang bermakna antar kelompok. Hal ini mungkin dipengaruhi oleh variasi rentang frekuensi pernapasan yang luas pada responden yang beragam usianya. Hasil penelitian ini sejalan dengan penelitian sebelumnya dimana tidak terdapat perbedaan bermakna saturasi oksigen dan frekuensi pernapasan antara posisi lateral dan posisi lain. ${ }^{16}$ Rentang frekuensi pernapasan pada anak-anak sangat berbeda antara berbagai kelompok usia. ${ }^{17}$ Selain itu, jumlah responden masih kurang sehingga perlu ditingkatkan untuk penelitian selanjutnya.

Perlu ditekankan bahwa perbedaan yang bermakna secara statistik tidak berarti bermakna secara klinis. Perbedaan yang signifikan secara klinis merujuk pada implikasi dari intervensi yang diberikan yang mampu memengaruhi keputusan perawatan. ${ }^{18}$ Pada komponen saturasi oksigen, rerata sebelum dan sesudah serta selisih antar kelompok masih dalam batas nilai yang sama atau normal $(98 \%$ menjadi $98,5 \%)$, hal ini menunjukan skor saturasi oksigen anak termasuk kategori normoxia. ${ }^{19}$ sehingga tidak memberikan makna pada keputusan perawatan anak selanjutnya. Sesuai dengan kriteria inklusi, anak yang direkrut di dalam penelitian ini memiliki gangguan pemenuhan kebutuhan oksigenasi yang ditandai dengan sesak meskipun sebagian besar memiliki saturasi oksigen di atas $94 \%$ dengan nilai PEWS di bawah 3. Pada anak dengan gangguan pemenuhan kebutuhan 
oksigenasi, nilai saturasi oksigen saja tidak menentukan derajat keparahan penyakit. Hal lain yang perlu diperhatikan meliputi skor klinis, frekuensi pernapasan, adanya suara napas abnormal, retraksi dan dispnea diperlukan untuk mendukung data saturasi oksigen anak. ${ }^{20}$

Pada anak dengan gangguan pemenuhan oksigenasi, target utama perawatan adalah frekuensi pernapasan anak dalam batas normal, anak tidak sesak dan terjadi peningkatan saturasi. ${ }^{21}$ Hipoksemia merupakan komplikasi umum dan faktor risiko besar untuk kematian pada anak dengan gangguan pernapasan. ${ }^{22}$ Untuk mencegah anak masuk ke dalam kondisi hipoksemia, tujuan asuhan keperawatan pada anak dengan gangguan pernapasan meliputi anak mampu mempertahankan kepatenan jalan napas, bebas dari sekresi dan obstruksi, anak tidak kesulitan bernapas, frekuensi pernapasan dalam batas normal, saturasi oksigen $>94 \% .{ }^{23}$ Posisi lateral diketahui meningkatkan ukuran jalan napas atas pada anak dalam kondisi sedasi. ${ }^{24}$ Penelitian sebelumnya menunjukkan bahwa dibandingkan dengan posisi prone, pada anak balita posisi lateral kanan secara signifikan dapat meningkatkan saturasi oksigen dan menurunkan frekuensi pernapasan. ${ }^{25}$ Pada anak dengan infeksi bilateral paru, posisi lateral kanan terbukti dapat meningkatkan saturasi oksigen dalam 40 menit pertama dibandingkan dengan posisi semi fowler $60^{0} .{ }^{13} \mathrm{Hal}$ ini mendukung hasil penelitian ini di mana setelah diberikan posisi lateral, frekuensi pernapasan anak menurun dan saturasi oksigen meningkat. Hasil penelitian ini dapat dijadikan justifikasi pemberian posisi lateral pada anak dengan gangguan pemenuhan kebutuhan oksigenasi di ruang rawat inap.

Keterbatasan study ini adalah masih belum homogennya sampel yang dipilih sehingga diperkirakan memengaruhi hasil perbandingan antara kelompok pemberian posisi lateral dan kontrol. Namun, jika dilihat dari perbedaan parameter pernapasan saturasi oksigen dan frekuensi pernapasan, posisi lateral dapat memberikan pengaruh bermakna terhadap perbaikan kondisi anak dengan gangguan pemenuhan kebutuhan oksigenasi. Untuk penelitian selanjutnya diharapkan mempertimbangkan aspek tersebut dalam studi yang akan dilakukan.

\section{Kesimpulan}

Pemberian posisi lateral dapat meningkatkan saturasi oksigen dan menurunkan frekuensi pernapasan 
pada anak dengan gangguan pemenuhan kebutuhan oksigenasi.

\section{Ucapan Terima Kasih}

Penulis mengucapkan terima kasih kepada Fakultas IImu Keperawatan Prodi Ners Spesialis Keperawatan Anak atas bimbingan dan arahannya dalam poses penulisan artikel ini.

\section{Daftar referensi}

1. WHO. Pneumonia. Published 2016. http://www.who.int/news-room/factsheets/detail/pneumonia

2. Tan KK, Dang DA, Kim KH, et al. Burden of hospitalized childhood community-acquired pneumonia: A retrospective cross-sectional study in Vietnam, Malaysia, Indonesia and the Republic of Korea. Hum Vaccin Immunother. 2018;14(1):95105. Available from:

http://search.ebscohost.com/login.a spx?direct=true \&db=mnh\&AN=291 25809\&site=ehost-live

3. Challands J, Brooks K. Paediatric respiratory distress. BJA Educ. 2019;19(11):350-356.

doi:10.1016/j.bjae.2019.07.004. Available from: https://pubmed.ncbi.nlm.nih.gov/33 456857

4. Flori HR, Glidden D V, Rutherford GW, Matthay MA. Pediatric acute lung injury: prospective evaluation of risk factors associated with mortality. Am J Respir Crit Care Med. 2005;171(9):995-1001.

5. Ebeledike C, Ahmad T. Pediatric Pneumonia. StatPearls Publishing [cited 2021 May 8]. Available from: https://www.ncbi.nlm.nih.gov/books /NBK536940/

6. Risteska-Nejashmikj V, Stojkovska $\mathrm{S}$, Stavrikj K. Dyspnea in children as a symptom of acute respiratory tract infections and antibiotic prescribing. Open Access Maced J Med Sci. 2018 Mar 14;6(3):578-81. Available from: $\quad$ https://pubmed.ncbi. nlm.nih.gov/29610624

7. Moore $\mathrm{Y}$, Shotton E, Brown R, Gremmel J, Lindsey S, Pankey J. Effects of Incentive Spirometry on Perceived Dyspnea in Patients Hospitalized With Pneumonia. MedSurg Nurs. 2018;27(1):19-37.

8. Schondelmeyer AC, Dewan ML, Brady PW, et al. Cardiorespiratory and pulse oximetry monitoring in hospitalized children: a delphi process. Pediatrics. 2020 Aug 1;146(2):e20193336. Available from: http://pediatrics. aappublications.org/content/146 /2/e20193336.abstract

9. Mezidi M, Guérin C. Effects of patient positioning on respiratory mechanics in mechanically 
ventilated ICU patients. Ann TransI

Med. 2018 Oct;6(19):384. Available

from: $\quad$ https://pubmed.ncbi.nlm.

nih.gov/30460258

10. Jung $H$, Kim HJ, Lee Y-C, Kim HJ. Comparison of Lateral And Supine Positions For Tracheal Extubation in Children: A Randomized Clinical Trial. Anaesthesist. 2019;68(5):3038. doi:10.1007/s00101-019-0590-2

11. Patil PS, Nagarwala R. A Comparative Study of Supine Lying, Side Lying And Prone Positioning On Oxygen Saturation, In Mechanically Ventilated Patients, In Acute Respiratory Failure. 2015;3(7):1627-31.

12. Coleman MD. Chapter 2 Respiratory and Pulmonary Physiology. In: Duke JBT-AS (Fourth E, ed. Mosby; 2011:17-23. Available from: https://www. sciencedirect.com/science/article/pi i/B9780323065245000027

13. Alan N, Khorshid L. The effects of different positions on saturation and vital signs in patients. Nurs Crit Care. 2021;26(1):28-34. Available from: https://doi.org/10.1111/nicc. 12477

14. Zhang X-W, Li Y, Zhou F, Guo C, Huang Z-T. Association of body position with sleep architecture and respiratory disturbances in children with obstructive sleep apnea. Acta
Otolaryngol. 2007;127(12):1321-6. Available from: https://doi.org/10.1080/000164807 01242451

15. Harika R, Radhika M, Indira S. A comparative study to evaluate the effectiveness of lateral position versus supine position on respiratory parameters among infants with respiratory problems. Int J Appl Res. 2015;1(12):935-40.

16. Gillies D, Wells D, Bhandari AP. Positioning for acute respiratory distress in hospitalised infants and children. Cochrane database Syst Rev. 2012;2012(7):CD003645CD003645. Available from: https://pubmed.ncbi. nlm.nih.gov/ 22786486

17. Fleming $S$, Thompson $M$, Stevens $R$, et al. Normal ranges of heart rate and respiratory rate in children from birth to 18 years of age: a systematic review of observational studies.

Lancet. 2011;377(9770):1011-8. Available from: http://dx.doi.org/10.1016/ S0140-6736(10)62226-X

18. Ranganathan $P$, Pramesh CS, Buyse M. Common pitfalls in statistical analysis: Clinical versus statistical significance. Perspect Clin Res. 2015;6(3):169.

19. Langley $R$, Cunningham $S$, Liverani ME, Cunningham S. How Should 
Oxygen Supplementation Be

Guided by Pulse Oximetry in

Children: Do we Know the Level?

Clinical Determination of. 2017;4(January).

doi:10.3389/fped.2016.00138

20. Kaya Z, Turktas(ogonek) I.

Correlation of clinical score to pulmonary function and oxygen saturation in children with asthma attack. Allergol Immunopathol (Madr). 2007;35(5):169-73. Available from: file:///03010546/00000035 00000005/v0_201402051228/1 3110310/v0_201402051228/en/ main.assets $E R$

21. Herdman TH, Kamitsuru S. NANDA International, Inc. nursing diagnoses: definitions \& classification 2018-2020. 2018.

22. Graham H, Bakare AA, Ayede $\mathrm{Al}$, et al. Hypoxaemia in hospitalised children and neonates: a prospective cohort study in Nigerian secondarylevel hospitals. EClinicalMedicine. $\quad$ 2019;16:5163. Available from: https://www.sciencedirect.com/ science/article/pii/S2589537019 301919.

23. Plouffe JA. Nursing care of the child with a respiratory disorder. Can Essentials Pediatr Nurs. Published online 2012:536-94.

24. Litman RS, Wake N, Chan L$M L$, et al. Effect of lateral positioning on upper airway size and morphology in sedated children. J Am Soc Anesthesiol. 2005;103(3):484-8.

25. Agustina $\mathrm{N}$, Nurhaeni $\mathrm{N}$, Hayati $\mathrm{H}$. Right lateral position can improving oxygen saturation and respiratory rate on under-five children with pneumonia. La Pediatr Medica e Chir. 2021;43(s1).

$\&$

